\title{
Forecasting Rice Production in Jigawa State, Nigeria using Fuzzy Inference System
}

\author{
${ }^{1 *}$ Ali Maianguwa Shuaibu, ${ }^{2}$ Maryam Nuraini Muhammad \\ and ${ }^{3}$ Yusuf Abu-Safyan \\ 1,2,3 Department of Mathematics, \\ Federal University Dutse, \\ Jigawa State, Nigeria
}

Email: Shuaibuali16@gmail.com

\begin{abstract}
In this work, we used fuzzy inference system to forecast rice production covering the period 20212030 in Jigawa state, Nigeria. This is done by designing a fuzzy inference system using MATLAB. The system consists of two input functions and a single output function. Each function has its membership functions from which 49 inference rules of the system were formed. Three variables were considered in the course of this research. The variables are rainfall, land and rice production. Furthermore, linguistic variables were defined on each input. A rule based system was then formed which is defuzzified and a crisp value is obtained as the forecasted value. The result of this research shows that in 2022, 177950ha is required with $873 \mathrm{~mm}$ of rainfall to produce $1070000 \mathrm{TN}$ of rice. Similarly, prediction is made of the required area, rainfall and rice yield up to 2030 in Jigawa state.
\end{abstract}

\section{INTRODUCTION}

Rice is one of the major staple foods in Nigeria, consumed across all geopolitical zones and socioeconomic classes (Kamai et al, 2020). Jigawa state is one of the major producers of rice in the country and the state has a projected population of 6,346,156 people as of 2018 (Ogunleye et al, 2018). Despite the huge comparative advantage enjoyed by Jigawa state including its 1.8 million hectares of cultivable land, over 0.4 million hectares of fertile fadama lands suitable for all-year round cultivation and a huge reservoir of bodies of water and able-bodied youths. The state is beset with a myriad of challenges (Jennifer, 2012).

To optimize the production of rice, scientific methods must be adopted through which the outcome of the production is predicted, this will enable proper allocation of funds, fertilizers, farm equipments and land to be used.

Kumar and Kumar (2015) compared the rule based system using fuzzy logic and the Kmeans algorithm for the prediction of crops yields. The two methods are then compared. Analysis of both predictions are done using the "MATLAB" software, and a valid conclusion is drawn as to which of the models is more accurate. The method is much more accurate than the prediction done by experienced farmers on the basis of assumption.

Though, there are quite a good number of prediction exercises reported in the literature (Jayaram and Marad, 2012), almost all of them are based on theory of statistics. Not much attempts seem to have been made in applying fuzzy reasoning in building input-output 
mappings related to crop yield estimation. Therefore, the intent of this work is set to apply the fuzzy inference system architecture for rice yield estimation.

\section{BACKGROUND OF THE RESEARCH}

If $X$ is a collection of objects $x$, then a fuzzy set $A$ in $X$ is defined as a set of ordered pairs:

$$
\mathrm{A}=\left\{\left(x, \mu_{A}(x)\right), x \in X\right\},
$$

where $\mu_{A}: X \rightarrow[0,1]$ is called the membership function (MF) for the fuzzy set $A$ and $\mu_{A}(x) \in[0,1]$ is the grade of membership of $x$ in $A$.

Fuzzy modelling is the standard method for constructing a fuzzy inference system (FIS). In general, we design a fuzzy inference system based on the past known behavior of a target system (Ross, 2010).

The most commonly used fuzzy inference technique is the so-called Mamdani method (Passino and Yurkovich, 1998). The Mamdani-style fuzzy inference process is performed in four steps: Fuzzification of the input variables, Rule evaluation (inference), Aggregation of the rule outputs (composition), and Defuzzification. The FIS used in this study is the Mamdani model and is built based on input and output variables with their respective membership functions and linguistic variables; the system follows a set of fuzzy membership rules after which a model is created using MATLAB.

Monthly rainfalls in $(\mathrm{mm})$ data were sourced from Jigawa State Agricultural and Rural Development Agency (JARDA), Dutse office. JARDA had been the only agency responsible for the collection and compilation of rainfall and agricultural data for over twenty (20) years in the state with weather stations in almost all the 27 local governments' area.

\section{Algorithm for Forecasting Rice Production}

In this work, a fuzzy inference system for production of rice is designed and the implementation is done on MATALB using the following steps:

1. Open MATLAB and type fuzzy on command window (Fig. 1),

2. Create a fuzzy inference system variable. In this case, rainfall and area as input and forecast as output (Fig. 2).

3. In this step, the linguistic variables are clearly defined and each linguistic variable defined is assigned to its fuzzy set, i.e., rainfall, area and production. Table 1, table 2 and table 3 gives the linguistic variables with its respective fuzzy sets.

4. Create the membership function by the use of triangular membership function (Fig. 3 , fig. 4 and fig. 5). The function uses a range of three values; lower limit, mid-point, and upper-limit.

5. Rule editor and viewer. The rule editor as shown in fig. 6 contains rules inputted based on the application of the FIS. The rules can be changed using the change button, deleted and also new rules can be added. The rules added are joined by either AND or OR operator. 


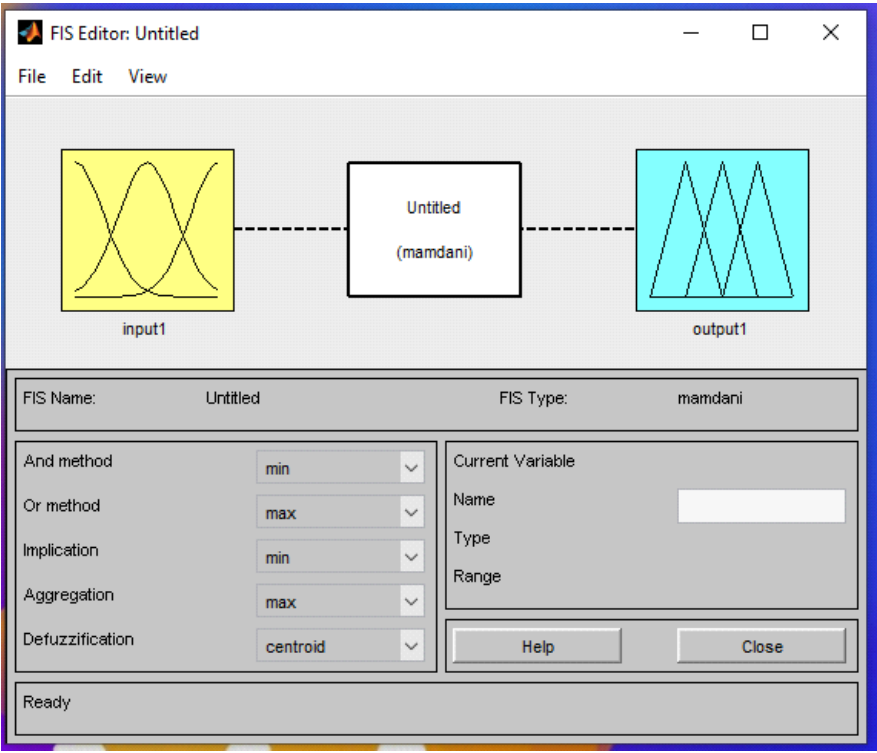

Figure 1: Fuzzy inference system on command window

Table 4 offers an explanation as to how the maximum and minimum value for each linguistic variable is defined. After the maximum and minimum value has been defined, a mid-point is found for each linguistic variable which is now applied to the fuzzy inference system.

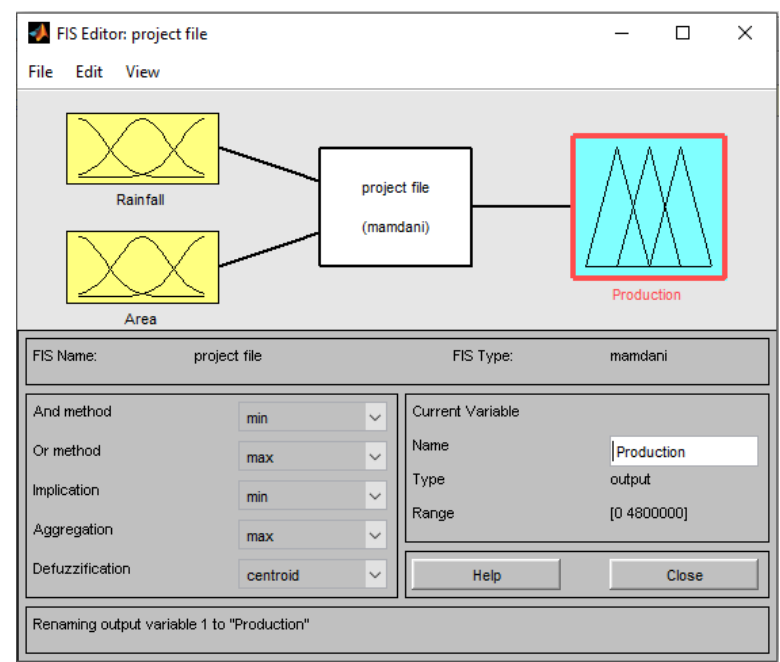

Figure 2: Fuzzy inference system variables

Table 1: Linguistic variables for rainfall

\begin{tabular}{|l|l|}
\hline Rainfall & Extremely light \\
\hline & Light \\
\hline & Below Moderate \\
\hline & Moderate \\
\hline & Rather Heavy \\
\hline & Heavy \\
\hline & Very Heavy \\
\hline
\end{tabular}


Table 2: Linguistic variables for area

\begin{tabular}{|l|l|}
\hline Area & Extremely less \\
\hline & Very less \\
\hline & Less \\
\hline & Less than average \\
\hline & Average \\
\hline & Good \\
\hline & Very good \\
\hline
\end{tabular}

Table 3: Linguistic variables for production

\begin{tabular}{|l|l|}
\hline $\begin{array}{l}\text { Production of } \\
\text { Rice }\end{array}$ & Extremely low \\
\hline & Very low \\
\hline & Low \\
\hline & $\begin{array}{l}\text { Less than } \\
\text { average }\end{array}$ \\
\hline & Average \\
\hline & Above average \\
\hline & Good \\
\hline & Very good \\
\hline & $\begin{array}{l}\text { Extremely } \\
\text { good }\end{array}$ \\
\hline
\end{tabular}

Table 4: Input variables

\begin{tabular}{|l|l|l|l|}
\hline INPUT & AMOUNT & MIN-VALUE & MAX-VALUE \\
\hline Rainfall & Extremely light & 0 & 228.5 \\
\hline & Light & 229 & 457 \\
\hline & Below Moderate & 458 & 685.5 \\
\hline & Moderate & 686 & 914 \\
\hline & Rather heavy & 915 & 1142.5 \\
\hline & Heavy & 1143 & 1371 \\
\hline & Very heavy & 1372 & 1600 \\
\hline Area & Extremely less & 0 & 57144 \\
\hline & Very less & 57145 & 114288 \\
\hline & Less & 114289 & 171432 \\
\hline & Less than average & 171432 & 228576 \\
\hline & Average & 228577 & 285720 \\
\hline & Good & 285721 & 342864 \\
\hline & Very good & 342864 & 400011 \\
\hline
\end{tabular}


Table 5: Output data

\begin{tabular}{|l|l|l|l|}
\hline OUTPUT & AMOUNT & MIN-VALUE & MAX-VALUE \\
\hline Production & Extremely low & 0 & 46667 \\
\hline & Very low & 46668 & 93334 \\
\hline & Low & 93335 & 140001 \\
\hline & Less than average & 140002 & 186668 \\
\hline & Average & 186669 & 233335 \\
\hline & Above average & 233336 & 280002 \\
\hline & Good & 280003 & 326669 \\
\hline & Very good & 326670 & 373336 \\
\hline & Extremely good & 373337 & 420000 \\
\hline
\end{tabular}

\section{Membership Function}

The membership function (MF) is a curve that shows the mapping of data input points into membership values that have an interval between 0 and 1 . One way that can be used to get membership value is through a functional approach (Wawan et al, 2021). A fuzzy set is completely characterized by its MF. In case of a single linguistic variable the MFs are onedimensional and combining the universes of different linguistic variables, MFs of higher dimensions may be derived.

In this work, the triangular MF is applied using MATLAB. A triangular MF, $\mu(\mathrm{x})$ is a function of a vector $x$, and specified by three parameters $\{a, b, c\}$ as follows:

$$
\mathrm{f}(x, a, b, c)= \begin{cases}0, & x \leq a \\ \frac{x-a}{b-a}, & a \leq x \leq b \\ \frac{c-x}{c-b}, & b \leq x \leq c \\ 0, & c \leq x\end{cases}
$$

It may also be described by min and max as

$$
\text { triangle }(x, a, b, c)=\max \left(\min \left(\frac{x-a}{b-a}, \frac{c-x}{c-b}\right), 0\right)
$$

The parameters a and c locate the "feet" of the triangle and b its peak. Triangular-shaped built-in membership function in the software MATLAB is used as shown:.

Matlab sytan $x: y=\operatorname{trimf}(x$, params $)$

$$
y=\operatorname{trimf}(x,[a b c])
$$




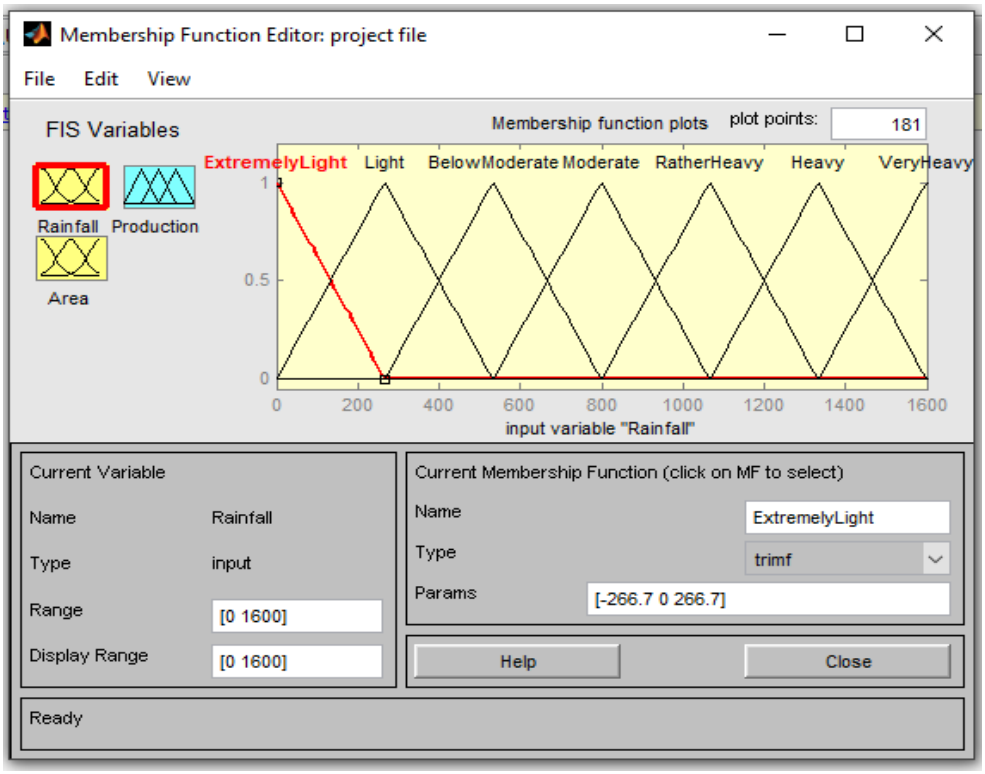

Figure 3: The membership function of rainfall

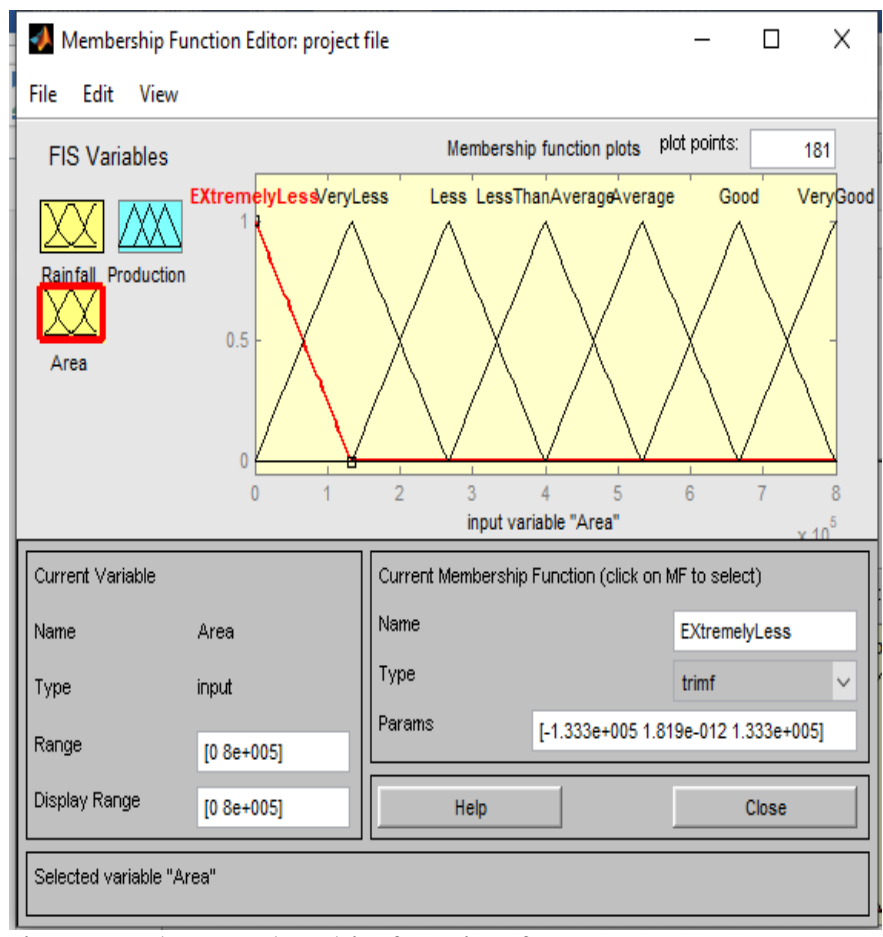

Figure 4: The membership function for Area 


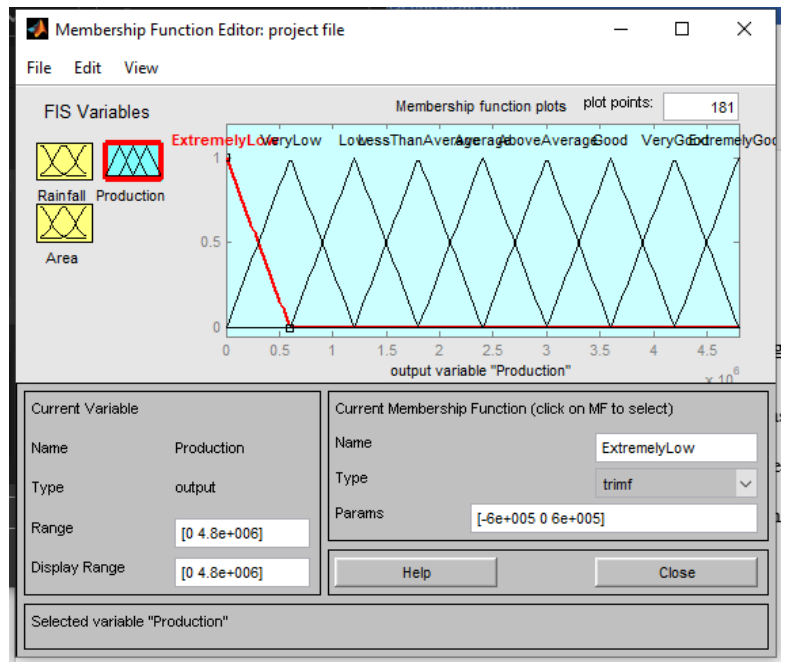

Figure 5: The membership function for rice production

There are 49 rules used in the FIS as listed below and demonstrated in fig. 6 .

i. If rainfall is extremely low and area is extremely less, then production is very low,

ii. If rainfall is moderate and area is average then production is above average,

iii. If rainfall is heavy and area is good then production is very good and so on.

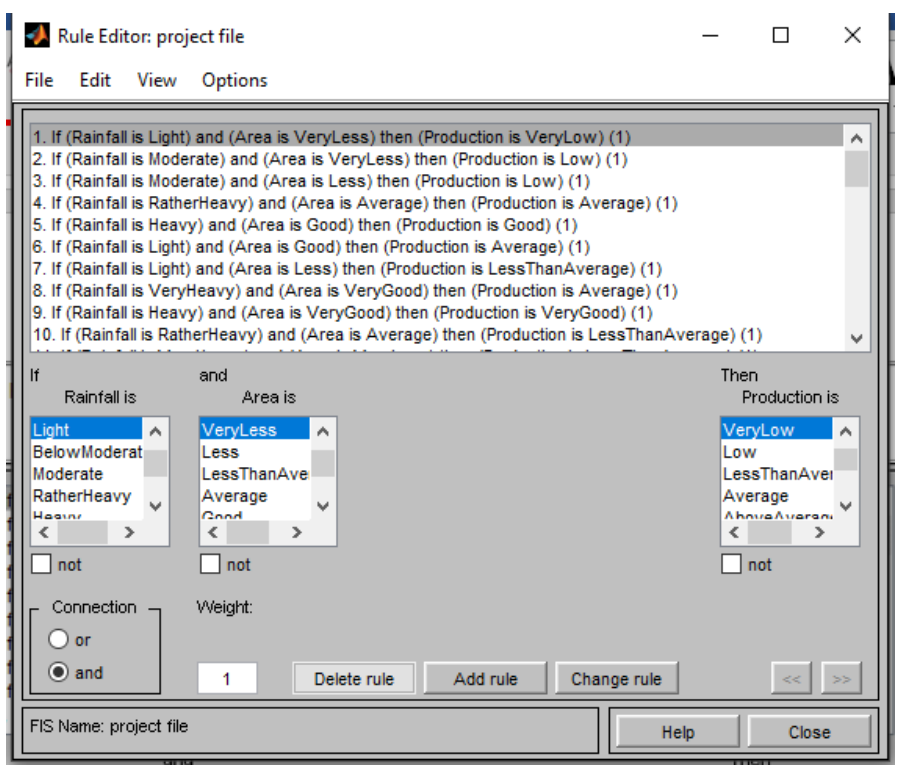

Figure 6: The rule editor

Rule viewer allows the input to see the effect of each input on the output based on the rules inputted which gives the defuzzified results (production of rice).

The rules used in the system are given as follows:

\begin{tabular}{|l|l|}
\hline$\#$ & \multicolumn{1}{|c|}{ RULES } \\
\hline 1 & If (Rainfall is Light) and (Area is VeryLess) then (Production is VeryLow) \\
\hline 2 & If (Rainfall is Moderate) and (Area is VeryLess) then (Production is Low) \\
\hline 3 & $\begin{array}{l}\text { If (Rainfall is Moderate) and (Area is Less) then (Production is Low) } \\
\text { Average) }\end{array}$ \\
\hline 4 & If (Rainfall is Heavy) and (Area is Good) then (Production is Good) \\
\hline 5 & If (Rainfall is Light) and (Area is Good) then (Production is Average) \\
\hline
\end{tabular}




\begin{tabular}{|c|c|}
\hline 7 & If (Rainfall is Light) and (Area is Less) then (Production is LessThanAverage) \\
\hline 8 & $\begin{array}{l}\text { If (Rainfall is VeryHeavy) and (Area is VeryGood) then (Production is } \\
\text { Average) }\end{array}$ \\
\hline 9 & If (Rainfall is Heavy) and (Area is VeryGood) then (Production is VeryGood) \\
\hline 10 & $\begin{array}{l}\text { If (Rainfall is RatherHeavy) and (Area is Average) then (Production is } \\
\text { LessThanAverage) }\end{array}$ \\
\hline 11 & $\begin{array}{l}\text { If (Rainfall is VeryHeavy) and (Area is VeryLess) then (Production is } \\
\text { LessThanAverage) }\end{array}$ \\
\hline 12 & If (Rainfall is Heavy) and (Area is Less) then (Production is Low) (1) \\
\hline 13 & If (Rainfall is Light) and (Area is VeryGood) then (Production is VeryLow) \\
\hline 14 & If (Rainfall is VeryHeavy) and (Area is Average) then (Production is Low) \\
\hline 15 & If (Rainfall is VeryHeavy) and (Area is Good) then (Production is Average) \\
\hline 16 & $\begin{array}{l}\text { If (Rainfall is RatherHeavy) and (Area is VeryGood) then (Production is } \\
\text { Average) }\end{array}$ \\
\hline 17 & If (Rainfall is Light) and (Area is VeryLess) then (Production is VeryLow) \\
\hline 18 & $\begin{array}{l}\text { If (Rainfall is Light) and (Area is Average) then (Production is } \\
\text { LessThanAverage) }\end{array}$ \\
\hline 19 & $\begin{array}{l}\text { If (Rainfall is RatherHeavy) and (Area is Average) then (Production is } \\
\text { Average) }\end{array}$ \\
\hline 20 & If (Rainfall is Heavy) and (Area is Less) then (Production is LessThanAverage) \\
\hline 21 & $\begin{array}{l}\text { lll is ExtremelyLight) and (Area is EXtremelyLess) then (Production is } \\
\text { yLow) }\end{array}$ \\
\hline 22 & $\begin{array}{l}\text { If (Rainfall is ExtremelyLight) and (Area is VeryLess) then (Production is } \\
\text { ExtremelyLow) }\end{array}$ \\
\hline 23 & $\begin{array}{l}\text { If (Rainfall is ExtremelyLight) and (Area is LessThanAverage) then } \\
\text { (Production is VeryLow) }\end{array}$ \\
\hline 24 & If (Rainfall is ExtremelyLight) and (Area is Less) then (Production is Low) \\
\hline 25 & $\begin{array}{l}\text { If (Rainfall is BelowModerate) and (Area is Less) then (Production is } \\
\text { LessThanAverage) }\end{array}$ \\
\hline 26 & $\begin{array}{l}\text { If (Rainfall is BelowModerate) and (Area is Average) then (Production is } \\
\text { LessThanAverage) }\end{array}$ \\
\hline 27 & $\begin{array}{l}\text { If (Rainfall is BelowModerate) and (Area is Good) then (Production is } \\
\text { Average) }\end{array}$ \\
\hline 28 & $\begin{array}{l}\text { If (Rainfall is VeryHeavy) and (Area is EXtremelyLess) then (Production is } \\
\text { ExtremelyLow) }\end{array}$ \\
\hline 29 & $\begin{array}{l}\text { If (Rainfall is VeryHeavy) and (Area is VeryLess) then (Production is } \\
\text { VeryLow) }\end{array}$ \\
\hline 30 & If (Rainfall is VeryHeavy) and (Area is Less) then (Production is Low) \\
\hline 31 & $\begin{array}{l}\text { If (Rainfall is VeryHeavy) and (Area is LessThanAverage) then (Production is } \\
\text { Average) }\end{array}$ \\
\hline 32 & $\begin{array}{l}\text { If (Rainfall is VeryHeavy) and (Area is Average) then (Production is } \\
\text { AboveAverage) }\end{array}$ \\
\hline 33 & If (Rainfall is VeryHeavy) and (Area is Good) then (Production is VeryGood) \\
\hline 34 & $\begin{array}{l}\text { If (Rainfall is VeryHeavy) and (Area is VeryGood) then (Production is } \\
\text { ExtremelyGood) }\end{array}$ \\
\hline 35 & $\begin{array}{l}\text { If (Rainfall is Heavy) and (Area is ExtremelyLess) then (Production is } \\
\text { ExtremelyLow) }\end{array}$ \\
\hline 36 & If (Rainfall is Heavy) and (Area is VeryLess) then (Production is VeryLow) \\
\hline 37 & If (Rainfall is Heavy) and (Area is VeryGood) then (Production is VeryGood) \\
\hline
\end{tabular}




\begin{tabular}{|c|l|}
\hline 38 & $\begin{array}{l}\text { If (Rainfall is Moderate) and (Area is LessThanAverage) then (Production is } \\
\text { Average) }\end{array}$ \\
\hline 39 & $\begin{array}{l}\text { If (Rainfall is Moderate) and (Area is Average) then (Production is } \\
\text { AboveAverage) }\end{array}$ \\
\hline 40 & $\begin{array}{l}\text { If (Rainfall is Moderate) and (Area is Good) then (Production is Good) } \\
\text { ExtremelyLow) }\end{array}$ \\
\hline 42 & $\begin{array}{l}\text { If (Rainfall is RatherHeavy) and (Area is VeryLess) then (Production is } \\
\text { VeryLow) }\end{array}$ \\
\hline 43 & $\begin{array}{l}\text { If (Rainfall is RatherHeavy) and (Area is LessThanAverage) then (Production } \\
\text { is AboveAverage) }\end{array}$ \\
\hline 44 & $\begin{array}{l}\text { If (Rainfall is RatherHeavy) and (Area is Average) then (Production is Good) } \\
\text { Average) }\end{array}$ \\
\hline 46 & $\begin{array}{l}\text { If (Rainfall is Heavy) and (Area is Average) then (Production is Good) } \\
\text { If (Rainfall is Heavy) and (Area is Good) then (Production is VeryGood) }\end{array}$ \\
\hline 47 & $\begin{array}{l}\text { If (Rainfall is VeryHeavy) and (Area is VeryGood) then (Production is } \\
\text { ExtremelyGood) }\end{array}$ \\
\hline 49 & $\begin{array}{l}\text { If (Rainfall is VeryHeavy) and (Area is VeryGood) then (Production is } \\
\text { ExtremelyGood) }\end{array}$ \\
\hline
\end{tabular}

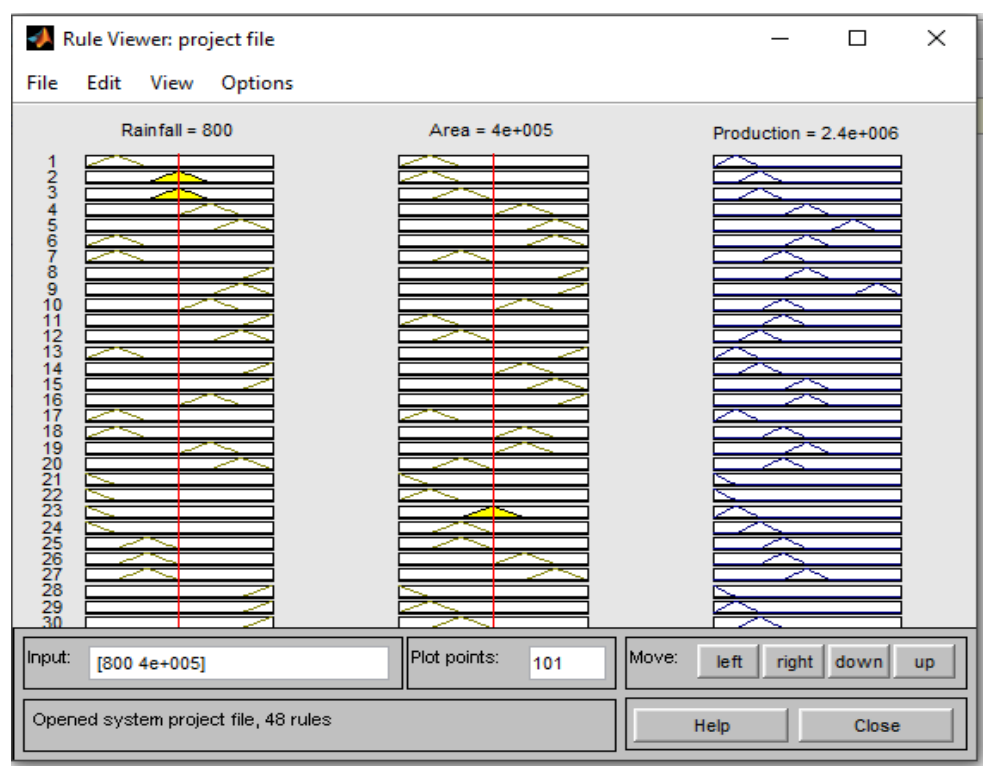

Figure 7: Rule viewer

The rule editor as shown in the figure 6 gives the prediction (forecast) for the rice production while simultaneously recommending the quantity of rainfall (water) to be applied on the provided area to ensure the forecasted value is achieved with minimum errors.

\section{RESULTS AND DISCUSSION}

The estimated cultivated area for rice in 2020 in Jigawa state was $117950 \mathrm{Ha}$, which represented an increase of about $2.24 \%$ over the 113150 Ha cultivated in 2019(NAERLS AND FMARD, 2020).This area cultivated in the year 2020 was used in the FIS to generate the land area required in the subsequent years and the corresponding rice yields up to 2030. The result from the implementation of the fuzzy inference system is shown in table 6 . 
Table 6: Recommended rainfall and Rice production

\begin{tabular}{|r|r|r|r|}
\hline \multicolumn{1}{|l|}{ Year } & Area(ha) & $\begin{array}{l}\text { Rainfall } \\
\text { (mm) }\end{array}$ & \multicolumn{1}{l|}{$\begin{array}{l}\text { Production } \\
\text { (tons) }\end{array}$} \\
\hline 2020 & 117950 & 727 & 756000 \\
\hline 2021 & 147950 & 844 & 826000 \\
\hline 2022 & 177950 & 873 & 1070000 \\
\hline 2023 & 207950 & 888 & 1340000 \\
\hline 2024 & 237950 & 932 & 1420000 \\
\hline 2025 & 267950 & 1108 & 1660000 \\
\hline 2026 & 297950 & 1138 & 1770000 \\
\hline 2027 & 327950 & 1152 & 1980000 \\
\hline 2028 & 357950 & 1182 & 2190000 \\
\hline 2029 & 387950 & 1314 & 2390000 \\
\hline 2030 & 417950 & 1343 & 2550000 \\
\hline
\end{tabular}

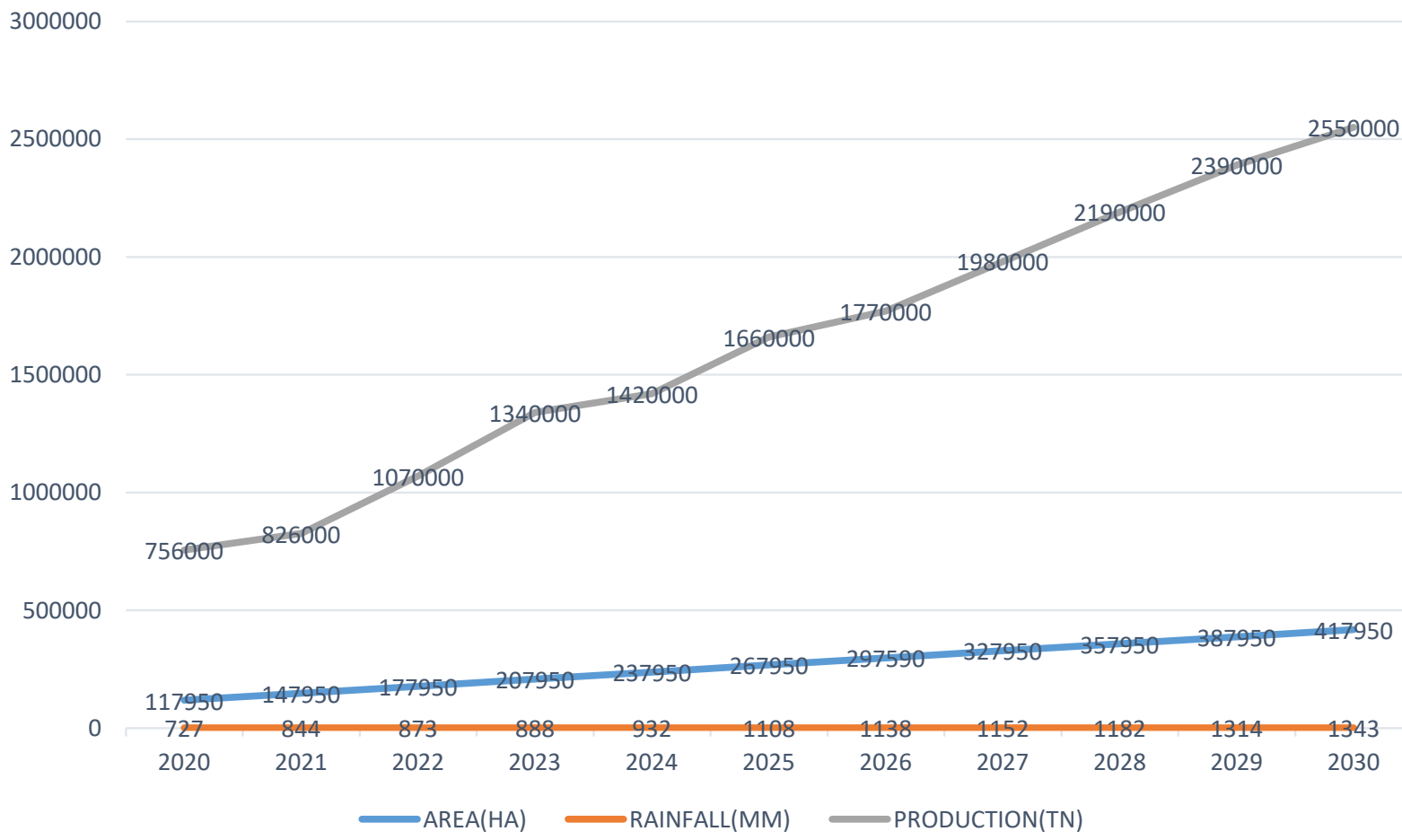

Figure 8: Relationship between rainfall, area and Rice production

Table 6 and graph in Figure 8 depicts the relationship between rainfall, area and rice production for a period 2020 to 2030.

It is shown that a farmer is required to get $727 \mathrm{~mm}$ of rainfall on 117950 ha of land in order to obtain a yield of $7560000 \mathrm{TN}$ of rice in the year 2020. If 147950 ha of land have been cultivated, $844 \mathrm{~mm}$ of rainfall is required for the area in order to obtain $826000 \mathrm{TN}$ of rice for 2021. In 2022, 177950 ha is required with $873 \mathrm{~mm}$ of rainfall to produce $1070000 \mathrm{TN}$ of rice. Similarly, prediction is made of the required area, rainfall and rice yield for up to 2030 in Jigawa state. 


\section{CONCLUSION}

This research presents application of FIS for analysis of yield of rice. It is aimed at achieving the prediction of rice production in Jigawa state from 2021-2030.The rice data set is initially processed and the crisp values are converted into fuzzy values in the stage of fuzzification. The FIS then executes rules to make a decision on yield of rice. Finally defuzzification is adopted to convert the fuzzy output set to a crisp output.

It is important to note that fuzzy logic applications hold potentials in agricultural operations. Most significant is the application of fuzzy logic in rice production under nondeterministic or stochastic environment. The uncertainties arise from difficulties of obtaining data, errors in measurement, imprecision or vagueness. In general, fuzzy sets theory is a very useful technique to increase effectiveness and efficiency of forecasting. The conventional time series is not applicable when the variable of time series are words variables (.i.e. variables with linguistic terms).

\section{References}

Jayaram, M.A. and Marad, N. (2012). Fuzzy Inference Systems for CropYield Prediction, J. Intell. Syst.21, 363-372.

Jennifer B. (2012). Hadejia Valley Mixed Economy, Jigawa State, Nigeria.

Kamai, N., Omoigui, L.O., Kamara, A.Y. , Ekeleme, F. (2020). Guide to Rice Production in Northern Nigeria. International Institute of Tropical Agriculture, Ibadan, Nigeria.

Kumar, A. and Kumar, S. (2015). Prediction of Production of Crops using K-mean \& Fuzzy Logic. International Journal of Computer Science and Mobile Computing, 4(8), August, 2015, 44-56.

NAERLS AND FMARD (2020). Wet Season Agricultural Performance in Nigeria, NAERLS Press, Zaria.

Ogunleye, G. O., Fashoto, S. G., Petros Mashwama Arekete, S. A., Olaniyan O. M. and Omodunbi B. A (2018) Fuzzy Logic Tool to Forecast Soil Fertility in Nigeria, Hindawi, The Scientific World Journal, Volume 2018.

Passino, K. M. and Yurkovich, S. (1998). Fuzzy control, Addison Wesley Longman, Inc.

Ross, T.J. (2010). Fuzzy Logic with Engineering Applications, Third Edition. John Wiley \& Sons, Ltd.

Wawan, W., Zuniati, M. and Setiawan, A. (2021). Optimization of National Rice Production with Fuzzy Logic using Mamdani Method, Journal of Multidisciplinary Applied Natural Science, 1(1). 